\title{
Ten questions concerning modeling of near-field pollutant dispersion in the built environment
}

\author{
Yoshihide Tominaga $^{\mathrm{a}}$ Ted Stathopoulos ${ }^{\mathrm{b}}$ \\ ${ }^{a}$ Niigata Institute of Technology, Kashiwazaki, Japan \\ ${ }^{b}$ Concordia University, Montreal, Canada \\ Corresponding author. E-mail address: tominaga@abe.niit.ac.jp (Y. Tominaga).
}

\begin{abstract}
Outdoor air pollution is a major current environmental problem. The precise prediction of pollutant concentration distributions in the built environment is necessary for building design and urban environmental assessment. Near-field pollutant dispersion, involving the interaction of a plume and the flow field perturbed by building obstacles, is an element of outdoor air pollution that is particularly complex to predict. Modeling methodologies have been discussed in a wide range of research fields for many years. The modeling approaches are categorized into field measurements, laboratory (wind and water tunnel) experiments, (semi-) empirical models, and computational fluid dynamics (CFD) models. Each of these approaches has advantages and disadvantages. It is therefore important to use due consideration for the underlying theory and limitations when applying these modeling approaches. This paper considers some of the most common questions confronting researchers and practitioners in the modeling of near-field pollutant dispersion in the built environment.
\end{abstract}

\section{Keywords}

Built environment; Computational fluid dynamics (CFD); Modeling technique; Near-field; Pollutant dispersion; Wind tunnel Experimentation

Introduction

Outdoor air pollution is a major environmental problem. In the built environment, both the outdoor exposure of pedestrians and the indoor exposure of building inhabitants to airborne pollutants are of interest [1]. The dispersion regions for pollutants in these scenarios are rather small, comprising the vicinity of the emitting building within a few hundred meters of the source, as opposed to a region of impact over the entire neighborhood. Such dispersion processes are called "near-field" pollutant dispersion, which differ significantly in properties from far-field dispersion, in which horizontal motion prevails over vertical motion and the influence of individual buildings on the dispersion field is small. Near-field pollutant dispersion concerns local emission sources and the dispersion of these emissions for scales of individual nearby buildings up to neighborhoods. Because near-field pollutant dispersion involves the interaction of plumes with flow fields perturbed by building obstacles, the phenomenon has both meteorological and building aerodynamic aspects. Furthermore, surrounding variables, such as stack configurations, rooftop structures, and topography, have non-negligible effects on pollutant distribution.

The modeling methods used for near-field pollutant dispersion have been discussed in a wide range of research fields for many years, as reviewed in several studies, e.g. [2-14]. Approaches to the problem are categorized into field measurements, laboratory (wind and water tunnel) experiments, (semi-) empirical models, and computational fluid dynamics (CFD) techniques. Full and reduced-scale field measurements have provided valuable information, because they use "real fluids" with "real atmospheric conditions." They have been conducted for many years, e.g. [15-18]; however, the boundary conditions of field measurements are neither controllable nor repeatable [19]. Therefore, the applicability of field data is limited for systematic and parametric studies. Laboratory experiments using wind and water tunnels are widely recognized as useful tools for predicting and analyzing pollutant dispersion, e.g. [20-21]. This approach also employs "real fluids"; however, the boundary conditions must be carefully modeled to resemble real atmospheric conditions. Because experimental conditions are highly controlled in laboratories, data obtained this way are far more suitable for parametric and systematic studies of various physical flow and dispersion processes. However, data can only be collected at a limited number of discrete positions, excepting non-intrusive area techniques, and the obtained results can suffer from similarity requirements. In cases where the buoyancy effect is not negligible, the law of 
similitude becomes quite complex.

Micro-scale CFD has been used often recently, e.g. [22-27], because it can provide whole flow and dispersion field data and be performed at full scale. The method does not suffer from similarity requirements and this is a great advantage. However, CFD is very sensitive to the chosen parameters and conditions; best practice guidelines are necessary to select these constraints appropriately. Furthermore, reliable experimental data are also required to validate the accuracy and uncertainty of CFD results. CFD approaches used in pollutant dispersion modeling are normally classified into two main types: Reynolds-Averaged Navier-Stokes (NS) equations (RANS) modeling and Large Eddy Simulation (LES). RANS solves the ensemble-averaged NS equations by turbulence modeling, which aims to model the entire spectrum of the turbulent eddies. If the flow is assumed to be statistically steady, ensemble averaging is equivalent to time-averaging (steady-RANS), but for time-dependent flows, the ensemble-averaged NS equations can be solved transiently (unsteady-RANS; URANS). The most widely used turbulence model in RANS is the standard $k-\varepsilon$ model (SKE) [28]. This model is well known for its robustness, economy, and reasonable accuracy for a wide range of turbulent flows. As the strengths and weaknesses of the SKE have become apparent for different flow geometries, modifications have been introduced to improve the performance of the model, e.g. [29, 30]. LES is based on the concept of separating turbulent motion into large and small-eddies. LES solves the large-eddy motion by the filtered NS equations governing the three-dimensional time-dependent motion. Turbulence modeling is only applied to small eddies by means of the so-called sub-grid scale (SGS) model. The Smagorinsky model is a well-known method commonly used for the SGS model [31]. The superiority of LES for flow around bluff bodies is based on the ability to capture the coherent structures derived from the large-eddy motion. The model is disadvantageous in consuming more computer time and storage than RANS

The above modeling approaches are often time-consuming, costly, and difficult to implement within practical turn-around periods. Empirical modeling methods based on dispersion theory have been widely used as a different approach for many comprehensive evaluations, because they can be designed to enable the expeditious calculation of many different cases. Semi-empirical models include the Atmospheric Dispersion Modeling System (ADMS) [32-35] and the American Society of Heating, Refrigerating and Air Conditioning Engineers (ASHRAE) model [36-38], among others. However, these have limited applicability and decreased accuracy concerning the details of building configurations and the surrounding environment.

Given that each modeling approach has particular advantages and limitations, these approaches should be used prudently according to the modeling concepts. It is also necessary to clarify the purpose of use and the accuracy required for a scenario before choosing a model. Therefore, it is important to utilize these modeling approaches by considering the balance among accuracy, cost, and the specific features of a target to be achieved. This review paper considers some of the most common questions confronting researchers and practitioners in the modeling of near-field pollutant dispersion in the built environment.

\section{Ten questions (and answers) concerning the modeling of near-field pollutant dispersion in the built environment}

\subsection{What is near-field pollutant dispersion in the built environment?}

Answer: Near-field pollutant dispersion in the built environment is characterized by the complex interaction of plumes with flow fields perturbed by building obstacles. The dispersion field contains local emission sources and the dispersion of the emissions in nearby individual buildings and the surrounding neighborhood.

Wind flow in the built environment is described by the interactions between atmospheric flow and that around buildings. Figure 1 presents a schematic of the wind-flow pattern around an isolated building [23, 39, 40]. The flow field contains various types of flow patterns, including a boundary layer flow, horseshoe vortex, stagnation flow, separation flow, and recirculating flow. Notably, this figure shows the average wind-flow pattern; the actual flow pattern exhibits pronounced transient features, such as the build-up and collapse of the separation/recirculation bubbles and periodic vortex shedding in the wake [23]. Figure 2 depicts the flow pattern at a street intersection where a tall building is located on the upwind side of one street [6]. The additional secondary flows created by the tall building both mix external air into the canopy and draw air from it, particularly at the rear face of the building.

The pollutant concentration distributions produced by such complex flow fields can differ significantly from those predicted by conventional diffusion formulae, such as the Gaussian-based models. Such formulae contain the implicit assumptions that the flow field has straight and parallel streamlines, modest velocity gradients, and distributions of turbulent energy and length scales resulting from surface features that remain unchanged over long distances [3]. Therefore, the prediction of such concentration fields is difficult, as conventional formulae cannot be applied. Modeling requires not only the basic knowledge of air pollution meteorology and dispersion but also an understanding of wind engineering and building aerodynamics, because wind and buildings can strongly affect plume behavior. Important parameters for dispersion around buildings include environment topography, e.g. [41, 42], building geometry, e.g. [43, 44], wind speed, e.g. [45, 46, 98], wind direction, e.g. [47, 
48], turbulence, e.g. [49, 50], atmospheric stability, e.g. [51, 52], temperature, e.g. [53, 54], solar radiation, e.g. $[55,56]$, and tree planting, e.g. [57, 58]. Furthermore, depending on the pollutant substance, the buoyancy, e.g. [59-62], chemical reactions, e.g. [63-65], particulate matters, e.g. [9, 66], and deposition of the pollutant, e.g. [67, 68], may have non-negligible effects.

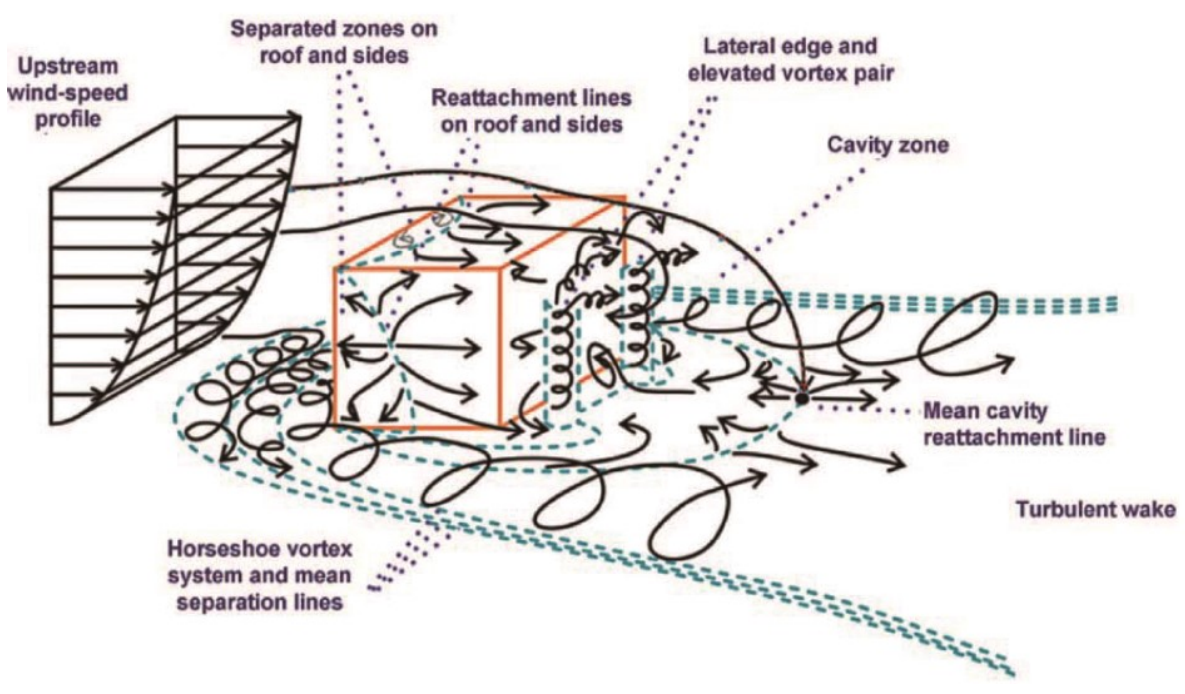

Figure 1. Schematic of the flow around an isolated low-rise building ([23]; modified from [39, 40]).

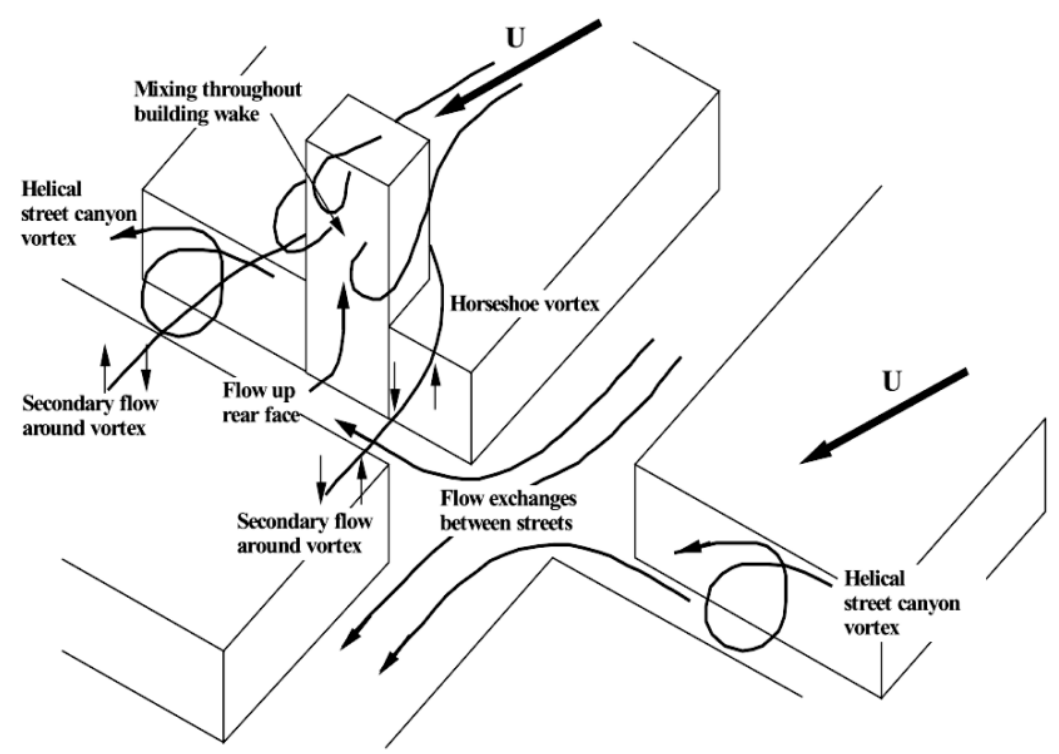

Figure 2. Flow field at a street intersection with a tall building, illustrating exchanges between the streets and the additional mixing processes due to the large building [6].

\subsection{How do the atmospheric boundary layer characteristics affect the dispersion of pollutants around buildings?}

Answer: As mentioned previously, the near-field dispersion around buildings is characterized by the interaction between atmospheric boundary layer flow and the flow around buildings. Therefore, modeling accurately the atmospheric boundary layer flow is imperative in order to obtain accurate and reliable predictions of the likely dispersion processes.

The approaching atmospheric boundary layer should be reproduced correctly in physical modeling. The common profiles representing wind speeds in atmospheric boundary layers follow logarithmic or power laws; 
the parameters in these profiles are connected to the classification of the upstream terrain [69, 70]. In practice, upstream surface roughness (sometimes combined with the presence of fences and spires) is used in order to simulate an approach wind profile in a wind tunnel [71-73].

In CFD, the accurate simulation of the atmospheric boundary layer flow in the computational domain is necessary in order to obtain accurate and reliable predictions of the related atmospheric process [74]. Within the computational domain, three different regions can usually be distinguished, as illustrated in Figure 3 [74]. Although the actual geometric shapes of features such as buildings are explicitly modeled in the central (target) region of the domain, these are modeled implicitly in the upstream and downstream regions. This means that they are not included in the domain, but their effects on the flow are modeled in terms of roughness in the upstream and downstream regions. Therefore, consistent modeling of the atmospheric boundary layer flow is important to avoid unintentional changes such as streamwise gradients or horizontal inhomogeneities that can occur in the vertical profiles of the mean wind speed and turbulence quantities as they travel from the inlet of the computational domain towards the target regions [74-82]. These unintentional inhomogeneities can dramatically affect the quality of the simulation results [74]. As many commercial CFD codes employ $k_{S}$-type wall functions, using the equivalent sand-grain roughness height $k_{S}$ as a parameter of roughness, Blocken et al. [74] derived specific relationships between $k_{S}$ and the aerodynamic roughness length $z_{0}$ for specific CFD codes and demonstrated the importance of satisfying these relationships in CFD simulations of wind flow around buildings. These methods are utilized in RANS simulations. For LES, special treatments are introduced to generate unsteady inflow turbulence, necessary for use as the boundary conditions. Several techniques have been developed for this purpose, and can be classified into three categories. The first and simplest is to store the time history of velocity fluctuations from a preliminary LES computation. The second is to set a driver section ahead of the main computational domain to generate inflow turbulence, e.g. [83-85]. The third is to generate inflow turbulence artificially, based on the inverse Fourier transform of prescribed spectra, e.g. [86-94]. Overall reviews of recent developments in engineering fields regarding these techniques can be found in [94, 95]. The influence of the atmospheric turbulence scales on dispersion will be important to the study of LES in the future, because it is difficult to reproduce the full-scale spectra over the entire range of wavelengths in wind tunnels.

As illustrated in Figure 4, while the approaching wind profile can be significantly deformed by building obstacles, the structure of the approaching wind affects the flow structure within the building canopy. Pedestrian-level flow conditions, even in a very built-up environment, are reported to be quite sensitive to the structure of the approaching wind [96]. Saathoff et al. [97] concluded through experimental work that high turbulence associated with an urban-type atmospheric boundary layer might increase plume dilution by as much as a factor of two compared to that measured in an open-country exposure. Several numerical studies have investigated the influence of atmospheric turbulence on pollutant diffusion around buildings, e.g. [49, 50, 99] and revealed that high inflow turbulence intensities reduced the pollutant concentration around buildings. High turbulence intensities cause significant turbulent diffusion around buildings, effectively diluting the pollutants. Furthermore, stratification effects on dispersion are not negligible, even under weakly unstable conditions in urban environments [51]. The effect of atmospheric stability on plume dispersion around buildings has been investigated by experimental, e.g. [100-103] and numerical, e.g. [51, 52, 104] studies. These results suggest that mean advection is more important than turbulent diffusion in pollutant dispersion when the turbulence weakens as stratification intensifies. 


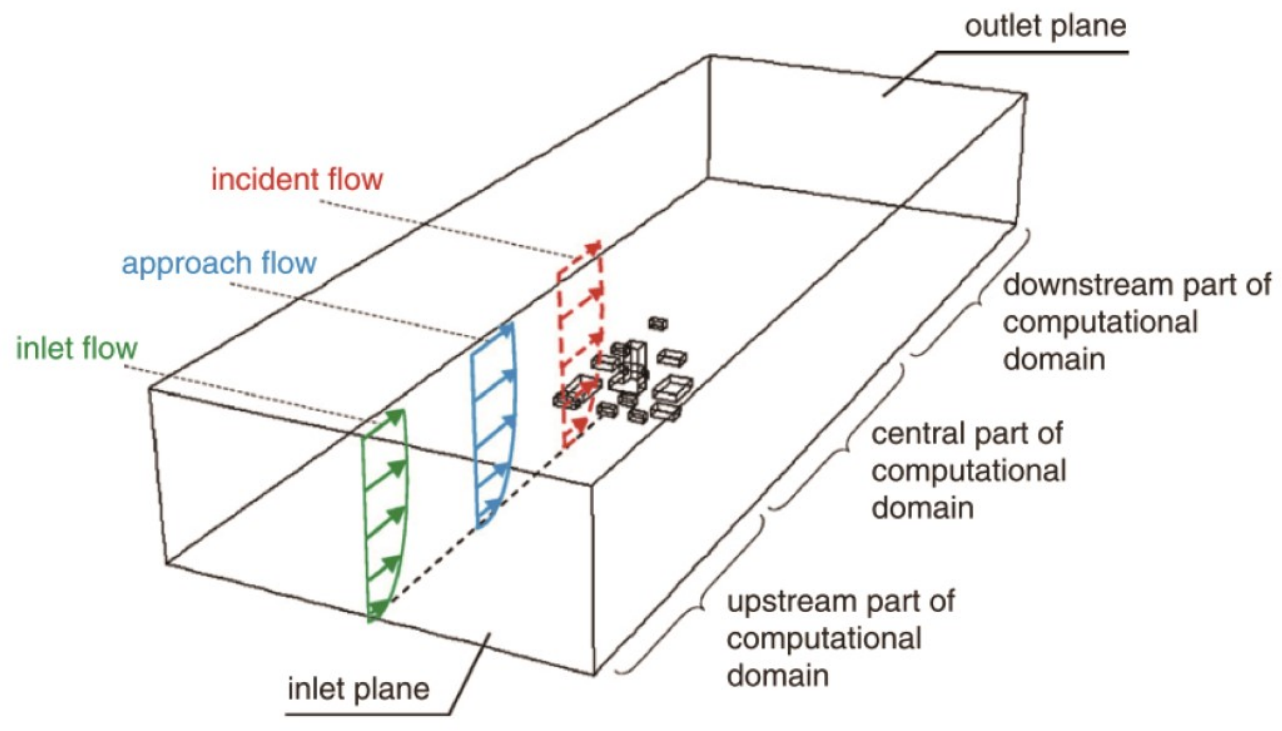

Figure 3. Computational domain with building models for CFD simulation of atmospheric boundary layer flow [74].

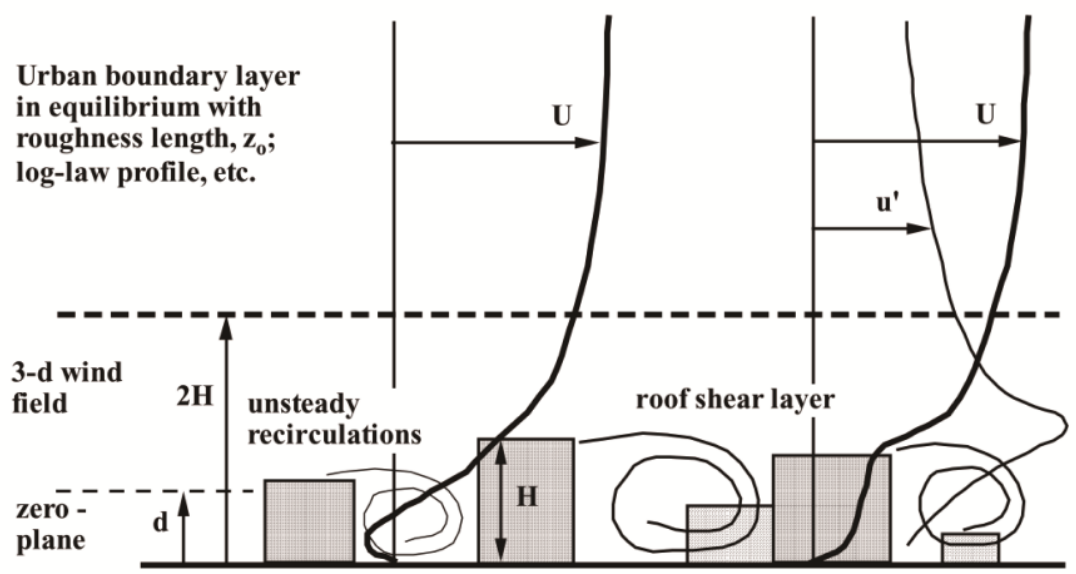

Figure 4. General features of the wind and turbulence fields over an urban area, showing regions of recirculation and ventilation $[6]$.

\subsection{How do surrounding variables like rooftop structures affect the pollutant dispersion around buildings?}

Answer: The presence of stack and rooftop structures affects airflow patterns around a building, possibly contributing to exhaust re-ingestion problems. In particular, the stack installed in wake flows and the downwash effect of a rooftop structure on a plume can reduce air quality by increasing pollutant concentration near a fresh-air intake [105-107].

Based on wind tunnel experiments, guidelines for the safe placement of stacks and intakes on various building surfaces to prevent exhaust re-ingestion were proposed by Hajra et al. [108]. A schematic of the suitability of intake locations on various building surfaces is illustrated in Figure 5. The existence of surrounding or adjacent buildings significantly influences pollutant dispersion. The following parameters affecting dispersion fields have been investigated in previous studies: Building dimensions, e.g. [109-113], configuration of adjacent buildings, e.g. [114-119], and roof geometry, e.g. [120-123]. 
a
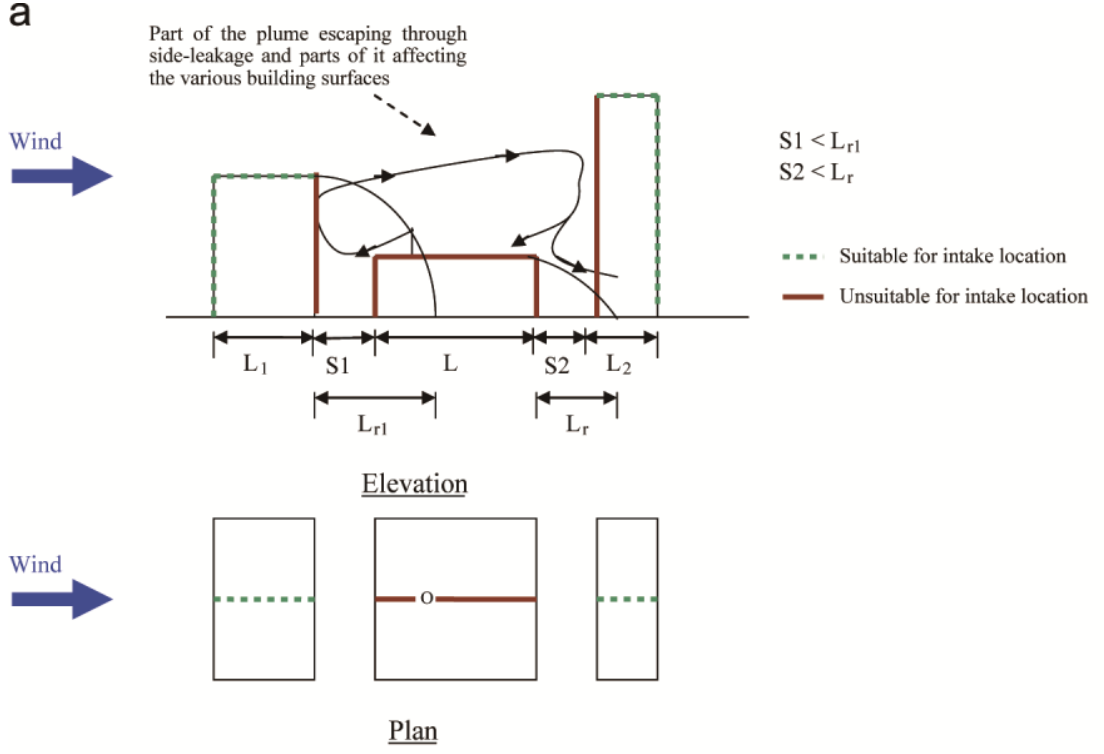

b
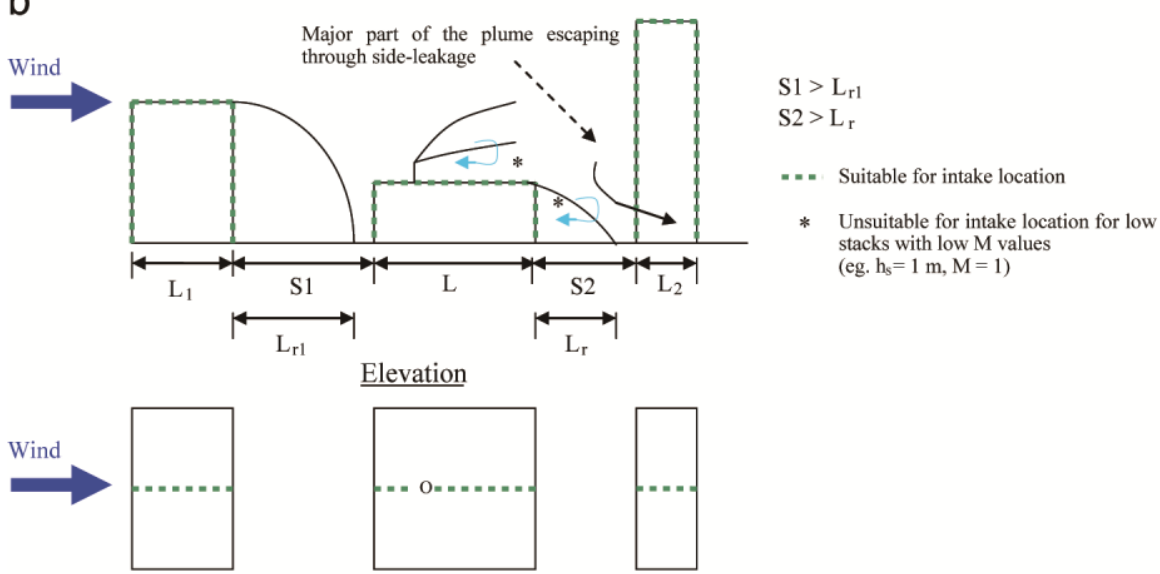

$\underline{\text { Plan }}$

Figure 5. Schematic for suitability of intake location at various building surfaces: (a) $\mathrm{S} 1<\mathrm{L}_{\mathrm{r} 1}$ and $\mathrm{S} 2<\mathrm{L}_{\mathrm{r}}$; (b) $\mathrm{S} 1>\mathrm{L}_{\mathrm{r} 1}$ and $\mathrm{S} 2>\mathrm{L}_{\mathrm{r}}[108]$.

\subsection{What are the important modeling parameters in physical experiments?}

Answer: The specification of dimensionless parameters guaranteeing similarity has been discussed extensively [8]. For reduced-scale dispersion experiments, the dynamic and thermal characteristics of an atmospheric boundary layer and an exhaust gas should be modeled. The following similitudes are considered: 1) model geometry, 2) flow field, and 3) gas emission. Detailed and important discussion about these issues can be found in [124-126].

For the model geometry, although the agreement is satisfied by model similarity, careful attention should be paid to the relationship between the model scale and the boundary-layer scale [126, 127]. For flow field similarity, based on dimensionless forms of the equations describing flow and dispersion with buoyancy, such as momentum, advection-diffusion of pollutant, and energy equations, the following well-known dimensionless numbers that must match between the real and modeled scales are derived:

$$
\text { Rossby number } R o \equiv \frac{U_{R}}{L \Omega_{R}}
$$

Densimetric Froude number $F r \equiv \frac{\Delta \rho L g}{\rho_{a} U_{R}^{2}}$ 
Reynolds number $R e \equiv \frac{U_{R} L}{v}$

Thermal Péclet number $P e \equiv \frac{U_{R} L}{\kappa}$

Mass transfer Péclet number $P e_{m} \equiv \frac{U_{R} L}{\alpha}$

Prandtl number $\operatorname{Pr} \equiv \frac{v}{\kappa}$

Schmidt number $S c \equiv \frac{v}{\alpha}$

Here, $\Omega_{\mathrm{R}}$ is the reference angular velocity of earth rotation, $\mathrm{U}_{\mathrm{R}}$ is the reference velocity, and $\mathrm{L}$ is the length. $\mathrm{g}$ is the gravitational acceleration, $\rho_{a}$ is air density, $\rho_{s}$ is the emission gas density, and $\Delta \rho=\rho_{s}-\rho_{a} . \nu$ is the kinematic viscosity, $\kappa$ is the thermal diffusivity, and $\alpha$ is the mass diffusivity.

Since the simultaneous satisfaction of all similarity requirements cannot be achieved, partial or approximate similitude must be used. Several of the dimensionless parameters can be neglected because they are low in importance relative to others when simulating transport and dispersion around buildings [8]. The Rossby number $(R o)$ represents the inertial effects of transport in a rotating coordinate system, such as the Earth. Although it is impossible to satisfy this requirement in a usual wind tunnel, it can be neglected because the inertial force is small relative to the Coriolis force, as the target area is small in a near-field dispersion study. The densimetric Froude number $(F r)$ indicates the ratio of the buoyancy force from the density difference between the exhaust gas and the ambient air to the inertial force; it is equivalent to the Richardson number. Since the agreement of $F r$ often leads to very low wind speeds in wind tunnels, it causes difficulties in the requirements for the Reynolds number $(R e)$. When $R e$ is large enough, the flow structures around bluff bodies with sharp edges are similar even if $R e$ is not identical, a phenomenon called "Reynolds Number Independence" [128]. The model and field values of the Prandtl $(P r)$ and Schmidt $(S c)$ numbers for wind-tunnel modeling of atmospheric flows are very similar. The thermal Péclet number $(P e)$ and mass transfer Péclet number $\left(P e_{m}\right)$ measure the ability of the fluid to advect heat or mass relative to the ability to disperse heat or mass by molecular transport. These parameters can also be expressed as $\operatorname{Re} \cdot \mathrm{Pr}$ or $\mathrm{Re} \cdot \mathrm{Sc}$. Therefore, $\mathrm{Pe}$ and $\mathrm{Pe}_{m}$ agreements are satisfied when the flow fields are turbulent enough. However, when wind speeds are very low in experiments, disagreement in these parameters may be problematic [59]. For gas emission, the following similarity parameters should be considered between the real and model fields: stack size, $F r$ of emission gases, density ratio of emission gases, and emission speed ratio [124, $125,129]$. When the buoyant force of the emission gas can be neglected, only the stack size and emission speed ratio are considered by using the tracer gas that has a density similar to that of air (such as ethylene or ethane). However, when the buoyant force of the emission gas cannot be neglected, the similitude becomes much more complicated. In such cases, the agreement of $F r$ among the emission gases is usually given priority over the other parameters, which are adjusted subserviently $[124,125]$. These criteria can become more important for the study of pollutant dispersion in coupled indoor and outdoor environments, because the length and velocity scales differ significantly between these environments.

The evaluation period is also important in physical experiments. Generally, because turbulent eddies in the atmospheric flow occur with various time and spatial scales, time-averaged concentrations change significantly based on the averaging times. Appropriate evaluation time scales differ depending on the intended contaminant release being modeled. A short-term emission, representing many accidental emission releases, is usually modeled as a puff or intermittent source. For this type of emission, the impact of short concentration peaks (lasting a few seconds on the real scale) should be evaluated. A peak-to-mean ratio and intermittency can be introduced in the evaluation [130]. However, a long-term emission, representing most flue-gas stack emissions, is usually modeled as a continuous source. Pollutant dispersion studies with this type of contaminant usually employ long averaging times.

Under what conditions can the Gaussian plume models be used?

Answer: The Gaussian plume-dispersion models assume that the vertical and crosswind dispersion of the plume are Gaussian in form, and include the effect of ground reflection of the plume. Most recent models utilize the Monin-Obukhov similarity theory to derive their model parameters. These models have been used for many comprehensive formal evaluations, because they are designed to enable many different cases to be calculated expeditiously, e.g. [32-35]. Furthermore, Gaussian models may include many complex dispersion processes, such as atmospheric stratification, buoyancy, chemistry, deposition, and concentration fluctuations.

One of the most widely used models is the ADMS, developed in England but also endorsed by the United States Environmental Protection Agency [32, 33]. This advanced dispersion model can calculate effluent 
concentrations emitted either continuously from point, line, volume, and area sources, or discretely from point sources. The model assumes concentration distributions to be Gaussian in neutral and stable conditions, but the vertical distributions are assumed non-Gaussian in convective conditions, to account for the skewed structure of the vertical component of turbulence [131]. In a study assessing the quality and applicability of various dispersion models for near-field dispersion, ADMS was the only model producing good comparisons with wind tunnel results. Other models, such as CALPUFF, SCREEN, and AFTOX, did not provide promising results for near-field dispersion in the built environment [132].

However, Hajra et al. [133] found that ADMS could not model the effects of rooftop structures, causing higher dilutions near the stack in comparison with wind tunnel results. The Gaussian-based empirical models could not explicitly treat detailed plume behaviors affected by building obstacles because of the modeling derivation. Therefore, in applying these models to near-field dispersion in urban environments, it is necessary to understand the fundamental concepts used in them $[134,135]$. The complex geometry, unsteady process, and short-time exposure, which cannot be specified when applying Gaussian-based plume models, may cause considerable errors in target areas where these effects are dominant.

Answer: The ASHRAE provides practical guidelines for the proper design of exhaust stacks and the placement of air intakes to avoid negatively affecting air quality in their Handbook. The ASHRAE model [36-38] consists of the two methods of geometric design and the Gaussian plume equations. The geometric design method is a qualitative approach, derived from the results of wind tunnel experiments, e.g. [114, 120] and it is typically used to assess the minimum stack height that can avoid plume re-ingestion through the roof or leeward wall of the emitting building. The geometric design method assumes that the plume, when released from a stack, follows a triangular path with a slope of 5:1 away from the centerline (Figure 6). The dimensions of the flow recirculation zones formed on the building are expressed in terms of $L_{r}$, the recirculation length formed in the wake of the building, which can be estimated using the dimensions of the building face perpendicular to the wind direction [120]. The boundary of the high-turbulence region is defined by a line with a slope of 10:1, extending from the top of the leading-edge separation bubble. The geometric design method has remained unchanged in the ASHRAE 2007, 2011 and 2015 versions. Meanwhile, the Gaussian plume equation is a quantitative technique used to estimate rooftop dilutions. Plume dilutions are estimated by calculating certain parameters, including the effective height of the plume above the roof, the exhaust velocity, the wind speed at building height, and plume spread standard deviations.

Notably, the Gaussian plume models have changed somewhat between the ASHRAE 2007 and 2011 versions, particularly in estimating plume dilutions. ASHRAE 2011 was recently introduced because discrepancies were observed between ASHRAE 2007 and experimental data from previous studies for cases of isolated buildings $[132,133]$. New formulations for estimating plume rise, plume spread parameters, and dilution for shorter time periods have been suggested. Hajra et al. [108] presented results from a wind tunnel study of near-field pollutant dispersion from the rooftop emissions of two multiple-building configurations. The dilutions obtained by the wind tunnel experiments were also compared to the ASHRAE 2007 and 2011 predictions. They found that ASHRAE 2007 predictions were overly conservative for the isolated building, while the ASHRAE 2011 estimates compared better with experimental data in some cases. However, as suggested by [117, 118], neither ASHRAE model is capable of modeling the effect of adjacent buildings; further investigation of the formulations underlying these models is required. There is no change in the Gaussian plume models between 2011 and 2015 versions.

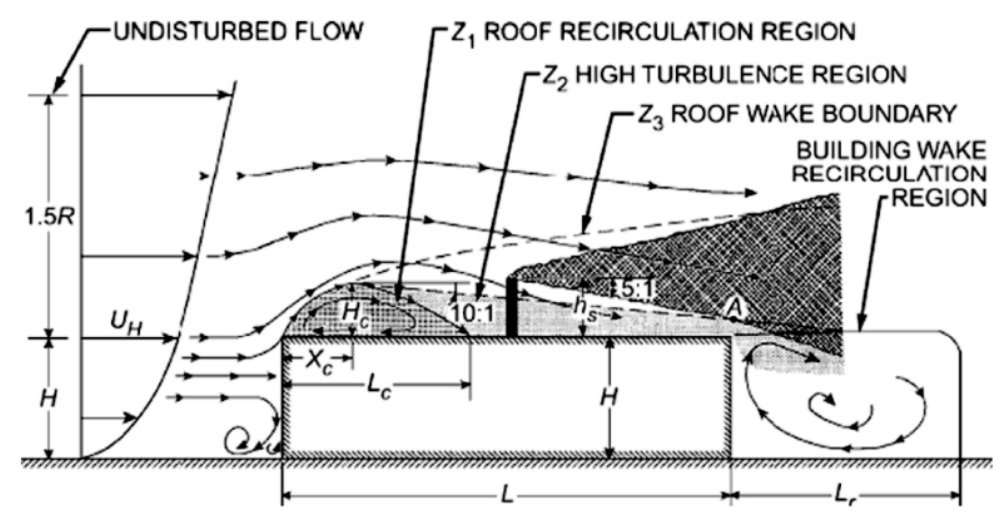

Figure 6. Design procedure for required stack height to avoid contamination [120]. 
Answer: CFD can overcome the disadvantages of full- and reduced-scale measurements in real atmospheric flow; in real conditions, variations in the wind and weather conditions cannot be controlled, so repeating an experiment under identical conditions is not possible. With CFD, these conditions can be set as boundary parameters. CFD can also overcome the disadvantages of wind tunnel testing, which generally only provides data for a limited number of discrete positions and can suffer from similarity requirements. CFD simulation is especially advantageous for stable atmospheric conditions and highly buoyant flows, as described in Section 2.4. Moreover, CFD is generally less expensive and time-consuming in setup, compared to the above approaches. However, CFD is disadvantageous in that it depends strongly on the computational parameters and conditions set during the simulation. Therefore, the accuracy and uncertainty of CFD are crucial. Both sensitivity analyses of the parameters and conditions as well as experimental validation studies are necessary for the utility of CFD results. The quality of results and computational time in CFD also depend crucially on the grid used to discretize the computational domain. The grid resolution should be fine enough to capture the important flow structures related to the pollutant dispersion, such as shear layers, vortices, and jets.

Researchers generally agree that both physical and numerical approaches are useful and should be complementary [14], by considering the advantages and limitations of multiple methods, e.g. [22-27, 136-138]. Given that the prediction accuracy of CFD in pollutant dispersion with highly buoyant flow fields has not been clarified yet, further studies are necessary in this area.

\subsection{How different are the simulation results obtained by steady-RANS and LES?}

Answer: According to previous studies comparing steady-RANS and LES for near-field dispersion modeling around buildings [139, 146], LES provides more accurate results than steady-RANS when calculating the mean distribution of concentration, although the difference between LES and RANS results for the mean velocities is not large. This is because the horizontal and vertical diffusion of concentrations are reproduced well by LES, because of the larger mixing effect of the large-scale velocity fluctuations behind the building [147]. Figure 7 illustrates the predicted results of pollutant dispersion by steady-RANS with RNG $k$ - $\varepsilon$ and LES from a stack located immediately downstream of an isolated rectangular building [145]. The average and instantaneous shapes of the plume are symbolized by the iso-surface $K=1$, where $K$ is the non-dimensional pollutant concentration. Because of large-scale fluctuations behind the building, as seen in the instantaneous plume shape (Fig. 7c), LES predicts that the average plume shape is shifted downwards and spread laterally (Fig. 7b), whereas RANS (RNG $k-\varepsilon$ ) predicts it to extend farther downstream without significant disturbances by the presence of the building (Fig. 7a). For cases in which advection effects are more prominent than those of diffusion, results obtained by steady-RANS are typically acceptable, assuming an appropriate turbulence model is selected. Figure 8 illustrates the results of concentration distributions by CFD (SKE and RNG $k-\varepsilon$ ) and experimental measurements [148] on the roof and wall surfaces with a downwind vent location [149]. Because most of the contaminant is advected by the strong separated flow in the streamwise direction in this case, the RNG, which successfully reproduces the reverse flow on the roof, provides good predictive concentrations in comparison with the SKE, which fails to reproduce the reverse flow. However, in cases where diffusion effects by large-scale coherent fluctuations around buildings, such as vortex shedding, are dominant, the steady-RANS significantly underestimates the pollutant diffusion.

In order to compensate for the underestimation of the mixing effect in steady-RANS, smaller values of the turbulent Schmidt number $\left(S c_{t}\right)$ are occasionally introduced, as discussed by Tominaga and Stathopoulos [150]. Because $S c_{t}$ is defined as the ratio of the eddy viscosity to the eddy mass diffusivity, increasing $S c_{t}$ leads to increases in eddy mass diffusivity. As demonstrated in many previous studies, e.g. [119, 144, 145, 151, 152], smaller $S c_{t}$ values often provide better results compared with experimental values. However, this cancellation of errors cannot be generalized and, therefore, is not recommended. The deficiency of steady-RANS is partly attributed to the shortcoming of the standard gradient diffusion hypothesis, e.g. [153, 154], and is partially improved by introducing higher-order closures for the turbulent scalar fluxes, e.g. [155-160]. However, the reproduction of unsteady large-scale fluctuations, captured only by unsteady computations, is more important in predicting near-field pollutant dispersion.

In addition, when an exhaust gas contains toxic, flammable, or odorous components, both the instantaneous and time-averaged concentrations are of interest. LES is advantageous in yielding important information on unsteady behavior of the concentration; this cannot be directly obtained by RANS computations neither by empirical models. 

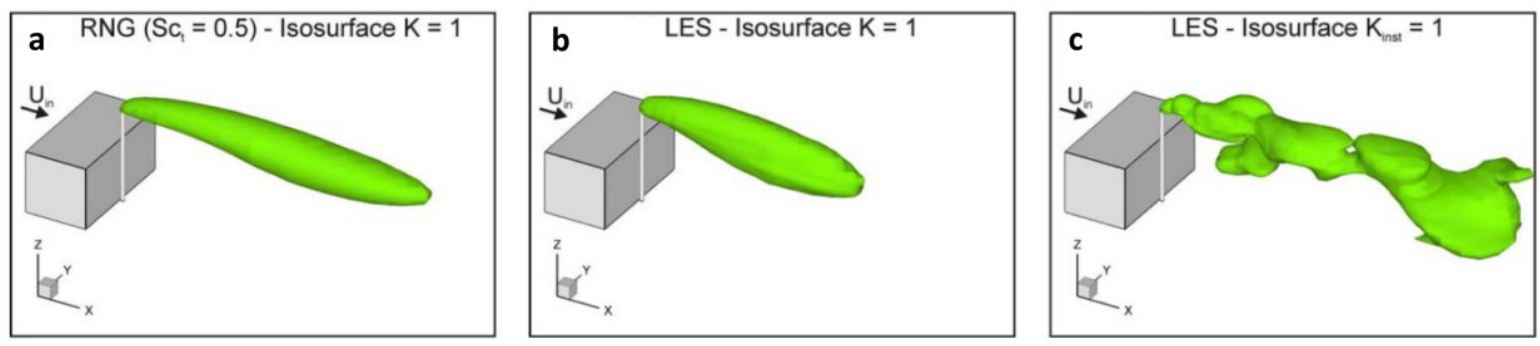

Figure 7. Average plume shapes obtained with (a) steady-RANS (RNG $k-\varepsilon$ ) (b) LES and (c) instantaneous plume shape obtained with LES ([145]; partly modified by the present authors).

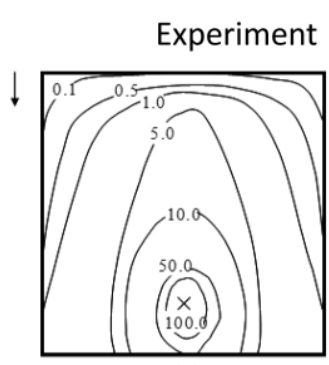

(a)

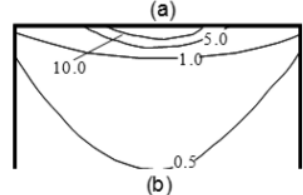

CFD (RNG k-E)

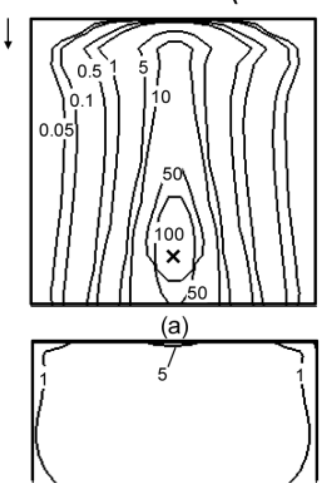

(b)

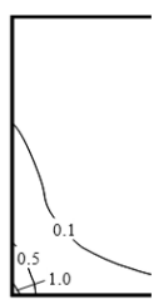

(c)

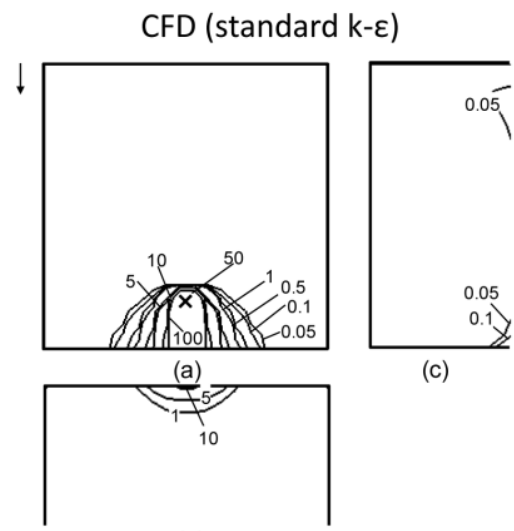

(b)

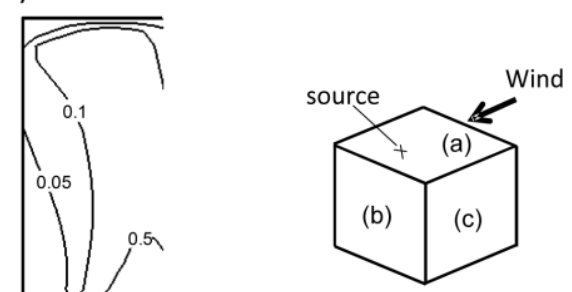

(c)

Figure 8. Contours of dimensionless concentration $K$ on roof surface, obtained by experiments [148] and CFD (downwind roof vent release) [149].

\subsection{Are there any validation databases for CFD simulation?}

Answer: In order to perform high-quality validations and uncertainty evaluations of CFD simulations, reliable experimental data are indispensable. It is particularly important that the required boundary conditions, such as inflow conditions, be provided for the computations. Several experimental datasets for near-field dispersion based on field and boundary layer wind tunnel experiments are available, as listed in Table 1.

Validation is the process of determining the degree to which a model accurately represents the real world regarding the intended uses of the model [164]. The fundamental strategy of validation relies on the identification and quantification of the error and uncertainty in both conceptual and computational models, quantification of the numerical error in computational solutions, estimation of experimental uncertainty, and comparison of computational results to the experimental data [165]. As suggested by Schatzmann and Leitl [19], the major source of uncertainty in field data relates to the question of measurement representativeness. The lack 
thereof is caused by the difference in the time scales of atmospheric turbulence and the duration of individual measurements with common averaging intervals of 10 or $30 \mathrm{~min}$. Therefore, in order to achieve data of known quality and uncertainty, as necessary for model validation, it is advisable to combine field measurements with corresponding laboratory measurements [19].

Moreover, as addressed by Harms [166], the validation of LES results is not as straightforward as that for models based on RANS. For LES, validation procedures are complicated because comparisons must be based not only on mean quantities but also on the frequency distributions of statistically representative ensembles of results.

Table 1. Validation database for near-field dispersion studies available online.

\begin{tabular}{|c|c|c|c|}
\hline Database & Measurement data & Refs. & URL \\
\hline $\begin{array}{l}\text { COST } 732 \text { Model } \\
\text { Evaluation Case } \\
\text { Studies }\end{array}$ & $\begin{array}{l}\text { Flow and concentrations for } \\
\text { MUST and Oklahoma City } \\
\text { cases (Wind tunnel) }\end{array}$ & {$[161,162]$} & $\begin{array}{c}\text { http://www.mi.zmaw.de/index.php?id= } \\
484 \\
\text { (Valid April, 2016) }\end{array}$ \\
\hline CODASC & $\begin{array}{l}\text { Concentrations around street } \\
\text { canyons with avenue-like tree } \\
\text { planting (Wind tunnel) }\end{array}$ & {$[57,58]$} & $\begin{array}{c}\text { http://www.windforschung.de/CODAS } \\
\text { C.htm (Valid April, 2016) }\end{array}$ \\
\hline CEDVAL & $\begin{array}{l}\text { Flow and concentrations around } \\
\text { isolated obstacles, regular arrays } \\
\text { of obstacles, and building } \\
\text { complex (Wind tunnel) }\end{array}$ & {$[163]$} & $\begin{array}{c}\text { http://www.mi.uni-hamburg.de/cedval/ } \\
\text { (Valid April, 2016) }\end{array}$ \\
\hline DAPPLE Datasets & $\begin{array}{l}\text { Flow and concentrations in the } \\
\text { complex urban environment in } \\
\text { central London (Field } \\
\text { measurements and Wind tunnel) }\end{array}$ & {$[16]$} & $\begin{array}{l}\text { http://www.dapple.org.uk/ } \\
\text { (Valid April, 2016) }\end{array}$ \\
\hline TPU Database & $\begin{array}{l}\text { Flow and concentrations around } \\
\text { an isolated building (Wind } \\
\text { tunnel) }\end{array}$ & {$[53]$} & $\begin{array}{c}\text { http://www.wind.arch.t-kougei.ac.jp/inf } \\
\text { o_center/pollution/pollution.html } \\
\text { (Valid April, 2016) }\end{array}$ \\
\hline
\end{tabular}

\subsection{Are there any best practice guidelines to follow in the CFD simulation?}

Answer: Several best practice guidelines exist to assist in achieving high-quality CFD simulations; these provide relevant information on the most important credibility issues, especially regarding the most common sources of errors and uncertainties in CFD, e.g. [164, 165, 167]. For urban wind environment applications, best practice guidelines have been proposed as verification and validation processes for CFD, intended for the prediction of wind field around buildings [77, 168-171]. General best practice advice was provided by Blocken and Gualtieri [172] for environmental fluid mechanics. Although these guidelines are effective in the near-field pollutant dispersion problem, additional recommendations are specific to the dispersion problem. These include the requirements of modeling for contaminant transport equations and sensitivities to computational parameters, e.g. $[145,150,152,173,174]$. While the above-mentioned guidelines focus on steady-RANS simulations, the establishment of appropriate practical guidelines for LES is underway. Gousseau et al. [175] have performed quality studies on external wind-flow around an isolated building, based on several influencing factors. Such studies could be extended to the dispersion problem and to more influencing factors. Recently, Ai and Mak [176] investigated the factors influencing the LES modeling of flow and dispersion around an isolated building. Hertwig et al. [177, 178] suggest and apply a novel validation strategy for LES, consisting of a multilevel hierarchy of comparative analysis methods, in which not only low-order statistical moments but also higher-order eddy statistics and structural turbulence information are compared.

\section{Summary and conclusions}

The modeling methods for the near-field pollutant dispersion have been discussed in wide-ranging research fields for many years. In this review paper, some common questions confronting researchers and practitioners in modeling near-field pollutant dispersion in the built environment were discussed. Modeling approaches were categorized into field measurements, laboratory (wind and water tunnels) measurements, (semi-) empirical models, and CFD models. The important points in the application of these methods are as follows:

- Both full- and reduced-scale field measurements have provided valuable information, because they use real fluids with real atmospheric conditions. However, the boundary conditions in such experiments are uncontrollable and not reproducible. Therefore, the applicability of the datasets obtained from field measurements is limited for systematic and parametric studies. 
- Laboratory experiments also employ real fluids; however, boundary conditions must be carefully modeled to resemble real atmospheric conditions. Because experimental conditions are easily controlled in the laboratory, results obtained from laboratory experiments are suitable for parametric and systematic studies of various physical flow and dispersion processes. However, the experiments can suffer from similarity requirements. In cases where thermal and buoyancy effects are non-negligible, the law of similitude becomes very complicated.

- Empirical modeling methods based on dispersion theory have been designed to enable the expeditious calculation of many different cases. The methods are relatively simple and easy to use but they have limited applicability and lower accuracy when building configuration details and the surroundings are considered.

- CFD can provide data for the entire flow and dispersion fields, performed at full scale and thus avoiding restrictions by similarity requirements. However, because CFD is very sensitive to the parameters and conditions, best practice guidelines are necessary to choose these aspects appropriately. Reliable experimental data are also required to validate the accuracy and uncertainty of CFD models.

- The existing modeling methods are best suited for steady pollutant distributions and relatively poor in modeling unsteady effects. However, CFD based on LES, which can overcome the limitations of the existing methods, may become a powerful tool in predicting and analyzing unsteady pollutant behavior. The establishment of appropriate practical guidelines and validation databases dedicated to LES are necessary but further research is required for their development.

Given that each modeling approach has distinct features and advantages, each method should be used in a manner appropriate to the modeling purpose. It is therefore important to use these modeling approaches while considering the underlying theory and limitations of the models. Current consensus is that both physical and numerical approaches are useful; they should be complementary in their advantages and limitations, thereby reducing the inaccuracy in the results of a single-approach method.

\section{Acknowledgements}

The authors would like to express their gratitude to Prof. Dr. Bert Blocken, an associate editor of Building and Environment, for providing this precious opportunity to prepare this paper. Sincere thanks also go to the anonymous reviewers for their valuable comments and suggestions.

\section{Biography}

Yoshihide Tominaga is a professor of the Department of Architecture and Building Engineering at the Niigata Institute of Technology. His area of expertise is the numerical modeling of micro-scale wind flow and related processes in urban environments, including urban microclimates, air pollutant dispersion, pedestrian wind comfort, and snowdrift. Ted Stathopoulos is a professor of the Department of Building, Civil \& Environmental Engineering at Concordia University. His research has focused on wind engineering and building aerodynamics, including wind load, air pollutant dispersion, natural ventilation, and wind comfort using both experimental and numerical approaches. The authors have collaborated jointly on this topic for nearly 10 years and the outcomes of this collaboration have been published as several peer-reviewed journal papers.

\section{References}

[1] Blocken, B., Tominaga, Y., \& Stathopoulos, T., 2013. CFD simulation of micro-scale pollutant dispersion in the built environment. Building and Environment 64, 225-230.

[2] Turner, D.B., 1979. Atmospheric dispersion modeling - A critical review. Journal of the Air Pollution Control Association 29(5), 502-519.

[3] Meroney, R.N., 1982. Turbulent diffusion near buildings. In Engineering Meteorology. Edited by E. J. Plate, Elsevier Scientific Publishing Company, Amsterdam, 48-525.

[4] Meroney, R.N., 1990. Bluff-body aerodynamics influence on transport and diffusion. Journal of Wind Engineering \& Industrial Aerodynamics 33, 21-33.

[5] Schatzmann, M., Rafailidis, S., \& Pavageau, M., 1997. Some remarks on the validation of small-scale dispersion models with field and laboratory data. Journal of Wind Engineering \& Industrial Aerodynamics $67 \& 68,885-893$.

[6] Robins, A., \& Macdonald, R., 2001. Review of flow and dispersion in the vicinity of groups of buildings. ADMLC Annual Report 1998/99, NRPB-R322-AnnexB, Atmospheric Dispersion Modelling Liaison Committee.

[7] Vardoulakis, S., Fisher, B.E., Pericleous, K., \& Gonzalez-Flesca, N., 2003. Modelling air quality in street canyons: A review. Atmospheric Environment 37, 155-182.

[8] Meroney, R.N., 2004. Wind tunnel and numerical simulation of pollution dispersion: A hybrid approach, 
Proceedings of Croucher Advanced Study Institute, Hong Kong University of Science and Technology, 66, 6-10 December 2004.

[9] Holmes, N.S., \& Morawska, L., 2006. A review of dispersion modelling and its application to the dispersion of particles: An overview of different dispersion models available. Atmospheric Environment 40(30), 5902-5928.

[10] Fernando, H.J.S., Zajic, D., Sabatino, S. Di, Dimitrova, R., Hedquist, B., \& Dallman, A., 2010. Flow, turbulence, and pollutant dispersion in urban atmospheres. Physics of Fluids 22, 051301.

[11] Xia, Q., Niu, J., \& Liu, X., 2014. Dispersion of air pollutants around buildings: A review of past studies and their methodologies. Indoor and Built Environment 23(2), 201-224.

[12] Belcher, S.E., Coceal, O., Hunt, J.C.R., Carruthers, D.J., \& Robins, A.G., 2013. A review of urban dispersion modelling. Technical Report. ADMLC, UK, 96 pp. ISBN 9780859517348.

[13] Yazid, A.W.M., Sidik, N.A.C., Salim, S.M., \& Saqr, K.M., 2014. A review on the flow structure and pollutant dispersion in urban street canyons for urban planning strategies. Simulation 90(8), 892-916.

[14] Meroney, R.N., 2016. Ten questions concerning hybrid computational/physical model simulation of wind flow in the built environment. Building and Environment 96, 12-21.

[15] Allwine K.J., \& Flaherty J.E., 2006. Joint Urban 2003: Study overview and instrument locations. Tech. rep. Pacific Northwest National Laboratory, Washington, U.S.A.

[16] Wood, C.R., Barlow, J.F., Belcher, S.E., Dobre, A., Arnold, S.J., Balogun, A.A., Lingard, J.J.N., Smalley, R.J., Tate, J.E., Tomlin, A.S., Britter, R.E., Cheng, H., Martin, D., Petersson, F.K., Shallcross, D.E., White, I.R., Neophytou, M.K., \& Robins, A.G., 2009. Dispersion experiments in central London: The 2007 DAPPLE Project. Bulletin of the American Meteorological Society 90, 955-969.

[17] Mavroidis, I., Griffiths, R.F., \& Hall, D.J., 2003. Field and wind tunnel investigations of plume dispersion around single surface obstacles. Atmospheric Environment 37(21), 2903-2918.

[18] Rotach, M.W., Vogt, R., Bernhofer, C., Batchvarova, E., Christen, A., Clappier, A., \& Voogt, J.A., 2005. BUBBLE - an urban boundary layer meteorology project. Theoretical and Applied Climatology 81(3-4), 231-261.

[19] Schatzmann, M., \& Leitl, B., 2011. Issues with validation of urban flow and dispersion CFD models. Journal of Wind Engineering \& Industrial Aerodynamics 99, 169-186.

[20] Robins, A., 2003. Wind tunnel dispersion modelling some recent and not so recent achievements. Journal of Wind Engineering \& Industrial Aerodynamics 91, 1777-1790.

[21] Ahmad, K., Khare, M., \& Chaudhry, K.K., 2005. Wind tunnel simulation studies on dispersion at urban street canyons and intersections: A review. Journal of Wind Engineering \& Industrial Aerodynamics 93, 697-717.

[22] Li, X.X., Liu, C.H., Leung, D.Y.C., \& Lam, K.M., 2006. Recent progress in CFD modelling of wind field and pollutant transport in street canyons. Atmospheric Environment 40, 5640-5658.

[23] Blocken, B., Stathopoulos, T., Carmeliet, J., \& Hensen, J.L.M., 2011. Application of CFD in building performance simulation for the outdoor environment: An overview. Journal of Building Performance Simulation 4, 157-184.

[24] Tominaga, Y., \& Stathopoulos, T., 2013. CFD simulation of near-field pollutant dispersion in the urban environment: A review of current modeling techniques. Atmospheric Environment 79, 716-730.

[25] Di Sabatino, S., Buccolieri, R., \& Salizzoni, P., 2013. Recent advancements in numerical modelling of flow and dispersion in urban areas: A short review. International Journal of Environment and Pollution 52(3/4), 172-191.

[26] Blocken, B., 2014. 50 years of computational wind engineering: Past, present and future. Journal of Wind Engineering \& Industrial Aerodynamics 129, 69-102.

[27] Lateb, M., Meroney, R.N., Yataghene, M., Fellouah, H., Saleh, F., \& Boufadel, M.C., 2016. On the use of numerical modelling for near-field pollutant dispersion in urban environments: A review. Environmental Pollution 208, Part A, 271-283.

[28] Launder, B.E., \& Spalding, D.B., 1972. Mathematical models of turbulence, Academic Press, New York.

[29] Yakhot, V., Orszag, S.A., Thangam, S., Gatski, T.B., \& Speziale, C.G., 1992. Development of turbulence models for shear flows by a double expansion technique. Physics of Fluids A4, 1510-1520.

[30] Shih, T. H., Liou, W. W., Shabbir, A., Yang, Z., \& Zhu, J., 1995. A New k- $\varepsilon$ Eddy Viscosity Model for High Reynolds Number Turbulent Flows-Model Development and Validation. Computers \& Fluids 24(3), 227-238.

[31] Smagorinsky, J., 1963. General circulation experiments with the primitive equations I. The basic experiment. Monthly Weather Review 91 (3), 99-164.

[32] Carruthers, D.J., Holroyd, R.J., Hunt, J.C.R., Weng, W.-S., Robins, A.G., Apsley, D.D., Thompson, D.J., \& Smith, F.B., 1994. UK-ADMS: A new approach to modelling dispersion in the earth's atmospheric boundary layer. Journal of Wind Engineering \& Industrial Aerodynamics 52, 139-153.

[33] Carruthers, D.J., McKeown, A.M., Hall, D.J., \& Porter, S., 1999. Validation of ADMS against wind tunnel data of dispersion from chemical warehouse fires. Atmospheric Environment 33, 1937-1953. 
[34] Hanna, S.R., Egan, B.A., Purdum, J., \& Wagler, J., 2001. Evaluation of the ADMS, AERMOD, and ISC3 dispersion models with the OPTEX, Duke Forest, Kincaid, Indianapolis and Lovett field datasets. International Journal of Environment and Pollution 16, 301-314.

[35] Hall, D.J., Spanton, A.M., Bennett, M., Dunkerley, F., Griffiths, R.F., Fisher, B.E.A., \& Timmis, R.J., 2002. Evaluation of new generation atmospheric dispersion models. International Journal of Environment and Pollution 18, 22-32.

[36] ASHRAE, 2007. Building air intake and exhaust design, ASHRAE handbook: HVAC Applications, American Society of Heating, Refrigerating and Air-Conditioning Engineering Inc., Atlanta, USA, Chapter 44.

[37] ASHRAE, 2011. Building air intake and exhaust design, ASHRAE handbook: HVAC Applications (SI), American Society of Heating, Refrigerating and Air-Conditioning Engineers, Inc., Atlanta, USA, Chapter 45.

[38] ASHRAE, 2015. Building air intake and exhaust design, ASHRAE handbook: HVAC Applications (SI), American Society of Heating, Refrigerating and Air-Conditioning Engineers, Inc., Atlanta, USA, Chapter 45.

[39] Hunt, J. C. R., Abell, C. J., Peterka, J. A., \& Woo, H., 1978. Kinematical studies of the flows around free or surface-mounted obstacles; applying topology to flow visualization. Journal of Fluid Mechanics, 86, 179200.

[40] Hosker, R.P., 1984. Flow and diffusion near obstacles. In: D. Randerson (Ed). Atmospheric Science and Power Production. Office of Scientific and Technical Information, United States Department of Energy.

[41] Castro, I.P., \& Apsley, D.D., 1997. Flow and dispersion over topography: A comparison between numerical and laboratory data for two-dimensional flows. Atmospheric Environment 31(6), 839-850.

[42] Perry, S.G., 1992. CTDMPLUS: A dispersion model for sources near complex topography. Part I: Technical formulations. Journal of Applied Meteorology 31(7), 633-645.

[43] Kastner-Klein, P., \& Plate, E.J., 1999. Wind-tunnel study of concentration fields in street canyons. Atmospheric Environment 33, 3973-3979.

[44] Takano, Y., \& Moonen, P., 2013. On the influence of roof shape on flow and dispersion in an urban street canyon. Journal of Wind Engineering \& Industrial Aerodynamics 123, 107-120.

[45] Wilson, D.J., 1982. Critical wind speeds for maximum exhaust gas reentry from flush vents at roof level intakes. ASHRAE Transactions 88, 503-513.

[46] Nazridoust, K., \& Ahmadi, G., 2006. Airflow and pollutant transport in street canyons. Journal of Wind Engineering \& Industrial Aerodynamics 94, 491-522.

[47] Kim, J.J., \& Baik, J.J., 2004. A numerical study of the effects of ambient wind direction on flow and dispersion in urban street canyons using the RNG $\kappa-\varepsilon$ turbulence model. Atmospheric Environment 38, 3039-3048.

[48] Soulhac, L., Perkins, R.J., \& Salizzoni, P., 2008. Flow in a street canyon for any external wind direction. Boundary-Layer Meteorology 126(3), 365-388.

[49] Kim, J.J., \& Baik, J.J., 2003. Effects of inflow turbulence intensity on flow and pollutant dispersion in an urban street canyon. Journal of Wind Engineering \& Industrial Aerodynamics 91, 309-329.

[50] Gorlé, C., van Beeck, J., Rambaud, P., \& Van Tendeloo, G., 2009. CFD modelling of small particle dispersion: The influence of the turbulence kinetic energy in the atmospheric boundary layer. Atmospheric Environment 43(3), 673-681.

[51] Zhang, Y.Q., Arya, S.P.P., \& Snyder, W.H., 1996. A comparison of numerical and physical modeling of stable atmospheric flow and dispersion around a cubical building. Atmospheric Environment 30(8), 1327-1345.

[52] Xie, Z.-T., Hayden, P., \& Wood, C.R., 2013. Large-eddy simulation of approaching-flow stratification on dispersion over arrays of buildings. Atmospheric Environment 71, 64-74.

[53] Yoshie, R., Jiang, G., Shirasawa, T., \& Chung, J., 2011. CFD simulations of gas dispersion around high-rise building in non-isothermal boundary layer. Journal of Wind Engineering \& Industrial Aerodynamics 99, 279-288.

[54] Tsai, M.-Y., Chen, K.-S., \& Wu, C.-H., 2005. Three-dimensional modeling of air flow and pollutant dispersion in an urban street canyon with thermal effects. Journal of the Air \& Waste Management Association 55(8), 1178-1189.

[55] Sini, J.-F., Anquetin, S., \& Mestayer, P.G., 1996. Pollutant dispersion and thermal effects in urban street canyons. Atmospheric Environment 30(15), 2659-2677.

[56] Kim, J.-J., \& Baik, J.-J., 1999. A numerical study of thermal effects on flow and pollutant dispersion in urban street canyons. Journal of Applied Meteorology 38, 1249-1261.

[57] Gromke, C., \& Ruck, B., 2007. Influence of trees on the dispersion of pollutants in an urban street canyon: Experimental investigation of the flow and concentration field. Atmospheric Environment 41, 3287-3302.

[58] Gromke, C., \& Ruck, B., 2009. On the impact of trees on dispersion processes of traffic emissions in street canyons. Boundary-Layer Meteorology 131, 19-34. 
[59] Meroney, R.N., 1988. Guidelines for fluid modeling of dense gas cloud dispersion. Journal of Hazardous Materials 17(1), 23-46.

[60] Mokhtarzadeh-Dehghan, M.R., Akcayoglu, A., \& Robins, A.G., 2012. Numerical study and comparison with experiment of dispersion of a heavier-than-air gas in a simulated neutral atmospheric boundary layer. Journal of Wind Engineering \& Industrial Aerodynamics 110, 10-24.

[61] Hu, L.H., Huo, R., \& Yang, D., 2009. Large eddy simulation of fire-induced buoyancy driven plume dispersion in an urban street canyon under perpendicular wind flow. Journal of Hazardous Materials 166(1), 394-406.

[62] Olvera, H.A., Choudhuri, A.R., \& Li, W.-W., 2008. Effects of plume buoyancy and momentum on the near-wake flow structure and dispersion behind an idealized building. Journal of Wind Engineering \& Industrial Aerodynamics 96(2), 209-228.

[63] Kwak, K.-H., Baik, J.-J., \& Lee, K.-Y., 2013. Dispersion and photochemical evolution of reactive pollutants in street canyons. Atmospheric Environment 70, 98-107.

[64] Bright, V.B., Bloss, W.J., \& Cai, X., 2013. Urban street canyons: Coupling dynamics, chemistry and within-canyon chemical processing of emissions. Atmospheric Environment 68, 127-142.

[65] Kikumoto, H., \& Ooka, R., 2012. A numerical study of air pollutant dispersion with bimolecular chemical reactions in an urban street canyon using large-eddy simulation. Atmospheric Environment 54, 456-464.

[66] Kumar, P., Robins, A., Vardoulakis, S., \& Britter, R., 2010. A review of the characteristics of nanoparticles in the urban atmosphere and the prospects for developing regulatory controls. Atmospheric Environment $44,5035-5052$.

[67] Chrysikopoulos, C.V., Hildemann, L.M., \& Roberts, P.V., 1992. A three-dimensional steady-state atmospheric dispersion-deposition model for emissions from a ground-level area source. Atmospheric Environment. Part A. General Topics 26(5), 747-757.

[68] Sutton, M.A. and 25 others, 1998. Dispersion, deposition and impacts of atmospheric ammonia: quantifying local budgets and spatial variability. Environmental Pollution 102(1), 349-361.

[69] Davenport, A.G., 1960. Rationale for determining design wind velocities. Journal of the Structural Division, Proceedings of the American Society of Civil Engineers 86, 39-68.

[70] Wieringa J., 1992. Updating the Davenport roughness classification. Journal of Wind Engineering \& Industrial Aerodynamics 41(1), 357-368.

[71] Counihan, J., 1967. An improved method of simulating an atmospheric boundary layer in a wind tunnel. Atmospheric Environment 3(2), 197-214.

[72] Davenport, A.G., \& Isymov, N., 1967. The application of the boundary layer wind tunnel to the prediction of wind loading. In Proceedings of the International Research Seminar: Wind Effects on buildings and Structures. Ottawa, Canada. 1, 201-230.

[73] Irwin, H.P.A.H., 1981. The design of spires for wind simulation. Journal of Wind Engineering \& Industrial Aerodynamics 7(3), 361-366.

[74] Blocken, B., Stathopoulos, T., \& Carmeliet, J., 2007. CFD simulation of the atmospheric boundary layer: Wall function problems. Atmospheric Environment 41, 238-252.

[75] Blocken, B., Carmeliet, J., \& Stathopoulos, T., 2007. CFD evaluation of wind speed conditions in passages between parallel buildings - Effect of wall-function roughness modifications for the atmospheric boundary layer flow. Journal of Wind Engineering \& Industrial Aerodynamics 95(9-11), 941-962.

[76] Richards P., \& Hoxey R., 1993. Appropriate boundary conditions for computational wind engineering models using the $\mathrm{k}-\varepsilon$ turbulence model. Journal of Wind Engineering \& Industrial Aerodynamics 46-47, 145-153.

[77] Franke J., Hellsten A., Schlunzen H., \& Carissimo B. (Eds), 2007. Best practice guideline for the CFD simulation of flows in the urban environment-COST Action 732, COST office, $52 \mathrm{pp}$.

[78] Hargreaves, D.M., \& Wright, N.G., 2007. On the use of the $\mathrm{k}-\varepsilon$ model in commercial CFD software to model the neutral atmospheric boundary layer. Journal of Wind Engineering \& Industrial Aerodynamics 95, 355-369.

[79] Yang, Y., Gu, M., Chen, S., Jin, X., Jin, H., Gu, M., \& Chen, S., 2009. New inflow boundary conditions for modelling the neutral equilibrium atmospheric boundary layer in computational wind engineering. Journal of Wind Engineering \& Industrial Aerodynamics 97, 88-95.

[80] Gorlé, C., van Beeck, J., Rambaud, P., \& van Tendeloo, G., 2009. CFD modelling of small particle dispersion: The influence of the turbulence kinetic energy in the atmospheric boundary layer. Atmospheric Environment 43, 673-681.

[81] Parente, A., Gorlé, C., Beeck, J., \& Benocci, C., 2011. A comprehensive modelling approach for the neutral atmospheric boundary layer: Consistent inflow conditions, wall function and turbulence model. Boundary-Layer Meteorology 140(3), 411-428.

[82] Richards, P.J., \& Norris, S.E., 2011. Appropriate boundary conditions for computational wind engineering models revisited. Journal of Wind Engineering \& Industrial Aerodynamics 99(4), 257-266.

[83] Lund, T.S., Wu, X., \& Squires, K.D., 1998. Generation of turbulent inflow date for spatially-developing 
boundary layer simulations. Journal of Computational Physics 140, 233-258.

[84] Kataoka, H., \& Mizuno, M., 2002. Numerical flow computation around aeroelastic 3D square cylinder using inflow turbulence. Wind and Structures 5 (2-4), 379-392.

[85] Liu, K.L., \& Pletcher, R.H., 2006. Inflow conditions for the large eddy simulation of turbulent boundary layer: A dynamic recycling procedure. Journal of Computational Physics 219(1), 1-6.

[86] Lee, S., Lele, S.K., \& Moin, P., 1992. Simulation of spatially evolving turbulence and the applicability of Taylor's hypothesis in compressible flow. Physics of Fluids A4(7), 1521-1530.

[87] Kondo, K., Murakami, S., \& Mochida, A., 1997. Generation of velocity fluctuations for inflow boundary condition of LES. Journal of Wind Engineering \& Industrial Aerodynamics 67\&68, 51-64.

[88] Maruyama, T., Rodi, W., Maruyama, Y., \& Hiraoka, H., 1999. Large eddy simulation of the turbulent boundary layer behind roughness elements using an artificially generated inflow. Journal of Wind Engineering and Industrial Aerodynamics 83, 381-392.

[89] Smirnov, R., Shi, S., \& Celik, I., 2001. Random flow generation technique for large eddy simulations and particle-dynamics modeling. Journal of Fluids Engineering 123, 359-371.

[90] Klein, M., Sadiki, A., \& Janicka, J., 2003. A digital filter based generation of inflow data for spatially developing direct numerical simulation or large eddy simulation. Journal of Computational Physics 186, 652-665.

[91] Mathey, F., Cokljat, D., Bertoglio, J.P., \& Sergent, E., 2006. Assessment of the vortex method for Large Eddy Simulation inlet conditions. Progress in Computational Fluid Dynamics, An International Journal 6 , 58-67.

[92] Xie, Z.-T., \& Castro, I.P., 2008. Efficient generation of inflow conditions for large eddy simulation of street-scale flows. Flow, Turbulence and Combustion 81, 449-470.

[93] Huang, S.H., Li, Q.S., \& Wu, J.R., 2010. A general inflow turbulence generator for large eddy simulation. Journal of Wind Engineering \& Industrial Aerodynamics 98, 600-617.

[94] Aboshosha, H., Elshaer, A., Bitsuamlak, G.T., \& Damatty, A.E., 2015. Consistent inflow turbulence generator for LES evaluation of wind-induced responses for tall buildings. Journal of Wind Engineering \& Industrial Aerodynamics 142, 198-216.

[95] Tabor, G.R., \& Baba-Ahmadi, M.H., 2010. Inlet conditions for large eddy simulation: A review. Computers \& Fluids 39, 553-567.

[96] Isyumov, N., \& Davenport, A.G., 1975. Comparison of full-scale and wind tunnel wind speed measurements in the commerce court plaza. Journal of Wind Engineering \& Industrial Aerodynamics 1, 201-212.

[97] Saathoff, P., Stathopoulos, T., \& Wu, H., 1998. The influence of freestream turbulence on nearfield dilution of exhaust from building vents. Journal of Wind Engineering \& Industrial Aerodynamics 77-78, 741-752.

[98] Huang, H., Akutsu, Y., Arai, M., \& Tamura, M., 2000. A two-dimensional air quality model in an urban street canyon: Evaluation and sensitivity analysis. Atmospheric Environment 34, 689-698.

[99] Kim, J., \& Baik, J., 2004. A numerical study of the effects of ambient wind direction on flow and dispersion in urban street canyons using the RNG k-epsilon model. Atmospheric Environment 38, 3039-3048.

[100] Higson, H.L., Griffiths, R.F., Jones, C.D. \& Biltoft, C., 1995. Effect of atmospheric stability on concentration fluctuations and wake retention times for dispersion in the vicinity of an isolated building. Environmetrics 6, 571-581. doi: 10.1002/env.3170060604

[101] Mavroidis, I., Griffiths, R.F., Jones, C.D., \& Biltoft, C.A., 1999. Experimental investigation of the residence of contaminants in the wake of an obstacle under different stability conditions. Atmospheric Environment 33, 939-949.

[102] Uehara, K., Murakami, S., Oikawa, S., \& Wakamatsu, S., 2000. Wind tunnel experiments on how thermal stratification affects flow in and above urban street canyons. Atmospheric Environment 34(10), 1553-1562.

[103] Santos, J.M., Reis Jr., N.C., Griffiths, R.F., \& Mavroidis, I., 2008. Experimental investigation of averaging time effects on building influenced atmospheric dispersion under different meteorological stability conditions. Building and Environment 44(6), 1295-1305.

[104] Santos, J.M., Reis Jr., N.C., Goulart, E.V., \& Mavroidis, I., 2009. Numerical simulation of flow and dispersion around an isolated cubical building: The effect of the atmospheric stratification. Atmospheric Environment 43(34), 5484-5492.

[105] Saathoff, P.J., Lazure, L.P., Stathopoulos, T., \& Peperkamp, H., 2002. The influence of a rooftop structure on the dispersion of exhaust from a rooftop stack, ASHRAE Transactions 108, 1029-1037.

[106] Saathoff, P., Gupta, A., Stathopoulos, T., \& Lazure, L., 2009. Contamination of fresh air intakes due to downwash from a rooftop structure. Journal of the Air \& Waste Management Association 59, 343-353.

[107] Gupta, A., Stathopoulos, T., \& Saathoff, P., 2012. Wind tunnel investigation of the downwash effect of a rooftop structure on plume dispersion. Atmospheric Environment 46, 496-507.

[108] Hajra, B., Stathopoulos, T., \& Bahloul, A., 2013. A wind tunnel study of the effects of adjacent buildings on near-field pollutant dispersion from rooftop emissions in an urban environment. Journal of Wind 
Engineering \& Industrial Aerodynamics 119, 133-145.

[109] Chan, A.T., So, E.S.P., \& Samad, S.C., 2001. Strategic guidelines for street canyon geometry to achieve sustainable street air quality. Atmospheric Environment 35 (32), 5681-5691.

[110] Liu, C.-H., Leung, D.Y.C., \& Barth, M.C., 2005. On the prediction of air and pollutant exchange rates in street canyons of different aspect ratios using large-eddy simulation. Atmospheric Environment 39, 1567-1574.

[111] Li, X.-X., Liu, C.-H., \& Leung, D.Y.C., 2008. Large-eddy simulation of flow and pollutant dispersion in high-aspect-ratio urban street canyons with wall model. Boundary-Layer Meteorology 129(2), 249-268.

[112] Meroney, R.N., Pavageau, M., Rafailidis, S., \& Schatzmann, M., 1996. Study of line source characteristics for 2-D physical modelling of pollutant dispersion in street canyons. Journal of Wind Engineering \& Industrial Aerodynamics 62, 37-56.

[113] Garcia Sagrado, A.P., Van Beeck, J., Rambaud, P., \& Olivari, D., 2002. Numerical and experimental modelling of pollutant dispersion in a street canyon. Journal of Wind Engineering \& Industrial Aerodynamics 90, 321-339.

[114] Wilson D.J., Fabris I., \& Ackerman M.Y., 1998. Measuring adjacent effects on laboratory exhaust stack design. ASHRAE Transactions 88(1), 513-533.

[115] Assimakopoulos, V.D., ApSimon, H.M., \& Moussiopoulos, N., 2003. Numerical study of atmospheric pollutant dispersion in different two-dimensional street canyon configurations. Atmospheric Environment 37, 4037-4049.

[116] Xiaomin, X., Zhen, H., \& Jiasong, W., 2006. The impact of urban street layout on local atmospheric environment. Building and Environment 41(10), 1352-1363.

[117] Hajra, B., Stathopoulos, T., \& Bahloul, A., 2011. The effect of upstream buildings on near-field pollutant dispersion in the built environment. Atmospheric Environment 45, 4930-4940.

[118] Hajra, B., \& Stathopoulos, T., 2012. A wind tunnel study of the effect of downstream buildings on near-field pollutant dispersion. Building and Environment 52, 19-31.

[119] Chavez, M., Hajra, B., Stathopoulos, T., \& Bahloul, A., 2011. Near-field pollutant dispersion in the built environment by CFD and wind tunnel simulations. Journal of Wind Engineering \& Industrial Aerodynamics 99, 330-339.

[120] Wilson D.J., 1979. Flow patterns over flat roofed buildings and application to exhaust stack design. ASHRAE Transactions 85, 284-295.

[121] Rafailidis, S., 1997. Influence of building area density and roof shape on the wind characteristics above a town. Boundary-Layer Meteorology 85, 255-271.

[122] Kastner-Klein, P., \& Rotach, M.W., 2004. Mean flow and turbulence characteristics in an urban roughness sublayer. Boundary-Layer Meteorology 111(1), 55-84.

[123] Huang, Y., Hu, X., \& Zeng, N., 2009. Impact of wedge-shaped roofs on airflow and pollutant dispersion inside urban street canyons. Building and Environment 44(12), 2335-2347.

[124] Snyder, W.H., 1972. Similarity criteria for the application of fluid models to the study of air pollution meteorology. Boundary-Layer Meteorology 3(1), 113-134.

[125] Snyder, W.H., 1979. Guideline for fluid modeling of atmospheric diffusion (No. EPA-450/4-79-016 (Draft)). Environmental Protection Agency, Research Triangle Park, NC, U.S.A.

[126] Obasaju, E. D., \& Robins, A. G., 1998. Simulation of pollution dispersion using small scale physical models-an assessment of scaling options. Environmental Monitoring and Assessment 52(1-2), 239-254.

[127] Saathoff, P.J., Stathopoulos, T., \& Dobrescu, M., 1995. Effects of model scale in estimating pollutant dispersion near buildings. Journal of Wind Engineering \& Industrial Aerodynamics 54/55, 549-559.

[128] Townsend, A.A., 1956. The structure of turbulent shear flow. Cambridge University Press, 429 pp.

[129] Huber, A. H., \& Snyder, W. H., 1982. Wind tunnel investigation of the effects of a rectangular-shaped building on dispersion of effluents from short adjacent stacks. Atmospheric Environment 16(12), $2837-$ 2848.

[130] Aubrun, S., \& Leitl, B., 2004. Unsteady characteristics of the dispersion process in the vicinity of a pig barn. Wind tunnel experiments and comparison with field data. Atmospheric Environment 38(1), 81-93.

[131] ADMS 3 user guide, 2004. Cambridge Environmental Research Consultants Limited, Cambridge, UK.

[132] Stathopoulos, T., Bahloul A, \& Hajra B., 2008. Analytical evaluation of dispersion of exhaust from rooftop stacks on buildings. IRSST research report R-576. Montreal, Canada, Institut de recherche Robert-Sauvé en santé et en sécurité du travail.

[133] Hajra, B., Stathopoulos, T., \& Bahloul, A., 2010. Assessment of pollutant dispersion from rooftop stacks: ASHRAE, ADMS and wind tunnel simulation. Building and Environment 45, 2768-2777.

[134] Riddle, A., Carruthers, D., Sharpe, A., McHugh, C., \& Stocker, J., 2004. Comparisons between FLUENT and ADMS for atmospheric dispersion modelling. Atmospheric Environment 38, 1029-1038.

[135] Antonioni, G., Burkhart, S., Burman, J., Dejoan, A., Fusco, A., Gaasbeek, R., Gjesdal, T., Jäppinen, A., Riikonen, K., Morra, P., Parmhed, O., \& Santiago, J.L., 2012. Comparison of CFD and operational dispersion models in an urban-like environment. Atmospheric Environment 47, 365-372. 
[136] Stathopoulos, T., 1997. Computational wind engineering: Past achievements and future challenges. Journal of Wind Engineering \& Industrial Aerodynamics 67-68, 509-532.

[137] Murakami, S., Ooka, R., Mochida, A., Yoshida, S., \& Kim, S.G., 1999. CFD analysis of wind climate from human scale to urban scale. Journal of Wind Engineering \& Industrial Aerodynamics 81, 57-81.

[138] Stathopoulos, T., 2002. The numerical wind tunnel for industrial aerodynamics: Real or virtual in the new millennium? Wind and Structures 5, 193-208.

[139] Dejoan, A., Santiago, J.L., Martilli, A., Martin, F., \& Pinelli, A., 2010. Comparison between large-eddy simulation and Reynolds-averaged Navier-Stokes computations for the MUST field experiment. Part II: Effects of incident wind angle deviation on the mean flow and plume dispersion. Boundary-Layer Meteorology 135, 133-150.

[140] Santiago, J.L., Dejoan, A., Martilli, A., Martin, F, \& Pinelli, A., 2010. Comparison between large-eddy simulation and Reynolds-averaged Navier-Stokes computations for the MUST field experiment. Part I: Study of the flow for an incident wind directed perpendicularly to the front array of containers. Boundary-Layer Meteorology 135, 109-132.

[141] Tominaga, Y., \& Stathopoulos, T., 2010. Numerical simulation of dispersion around an isolated cubic building: Model evaluation of RANS and LES. Building and Environment 45, 2231-2239.

[142] Tominaga, Y., \& Stathopoulos, T., 2011. CFD modeling of pollution dispersion in a street canyon: Comparison between LES and RANS. Journal of Wind Engineering \& Industrial Aerodynamics 99, 340-348.

[143] Tominaga, Y., \& Stathopoulos, T., 2012. CFD modeling of pollution dispersion in building array: Evaluation of turbulent scalar flux modeling in RANS model using LES results. Journal of Wind Engineering \& Industrial Aerodynamics 104-106, 484-491.

[144] Gousseau, P., Blocken, B., Stathopoulos, T., \& van Heijst, G.J.F., 2011. CFD simulation of near-field pollutant dispersion on a high-resolution grid: A case study by LES and RANS for a building group in downtown Montreal. Atmospheric Environment 45, 428-438.

[145] Gousseau, P., Blocken, B., \& van Heijst, G.J.F., 2011. CFD simulation of pollutant dispersion around isolated buildings: On the role of convective and turbulent mass fluxes in the prediction accuracy. Journal of Hazardous Materials 194, 422-434.

[146] Salim S.M., Buccolieri, R., Chan, A., \& Di Sabatino, S., 2011. Numerical simulations of atmospheric pollutant dispersion in an urban street canyon: Comparison between RANS and LES. Journal of Wind Engineering \& Industrial Aerodynamics 99, 103-113.

[147] Tominaga, Y., Mochida, A., Murakami, S., \& Sawaki, S., 2008. Comparison of various revised k- $\varepsilon$ models and LES applied to flow around a high-rise building model with 1:1:2 shape placed within the surface boundary layer. Journal of Wind Engineering \& Industrial Aerodynamics 96, 389-411.

[148] Li, W.-W., \& Meroney, R. N. 1983. Gas Dispersion near a Cubical Model Building. Part 1. Mean Concentration Measurements. Journal of Wind Engineering \& Industrial Aerodynamics 12, 15-33.

[149] Tominaga, Y., \& Stathopoulos, T., 2009. Numerical simulation of dispersion around an isolated cubic building: Comparison of various types of k- $\varepsilon$ models. Atmospheric Environment 43, 3200-3210.

[150] Tominaga, Y., \& Stathopoulos, T., 2007. Turbulent Schmidt numbers for CFD analysis with various types of flowfield. Atmospheric Environment 41, 8091-8099.

[151] Di Sabatino, S., Buccolieri, R., Pulvirenti, B., \& Britter, R., 2007. Simulations of pollutant dispersion within idealised urban-type geometries using CFD and integral models. Atmospheric Environment 41, 8316-8329.

[152] Blocken, B., Stathopoulos, T., Saathoff, P., \& Wang, X., 2008. Numerical evaluation of pollutant dispersion in the built environment: Comparisons between models and experiments. Journal of Wind Engineering \& Industrial Aerodynamics 96, 1817-1831.

[153] Dezs-Weidinger, G., Stitou, A., Beeck, J.V., \& Riethmuller, M.L., 2003. Measurement of the turbulent mass flux with PTV in a street canyon. Journal of Wind Engineering \& Industrial Aerodynamics 91, 1117-1131.

[154] Brown, M.J., 2004. Urban dispersion: Challenges for fast response modelling. 5th AMS Symposium on the Urban Environment, Vancouver, B.C., Canada, August 2004.

[155] Launder, B.E., 1978. Heat and mass transport. In Turbulence, 2nd Ed., P. Bradshaw, ed., Springer- Verlag, Berlin.

[156] Rogers, M.M., Mansour, N.N., \& Reynolds, W.C., 1989. An algebraic model for the turbulent flux of a passive scalar. Journal of Fluid Mechanics 203, 77-101.

[157] Abe, K., \& Suga, K., 2001. Toward the development of a Reynolds-averaged algebraic turbulent scalar flux model. International Journal of Heat and Fluid Flow 22, 19-29.

[158] Younis, B.A., Speziale, C.G., \& Clark, T.T., 2005. A rationale model for the turbulent scalar fluxes. Proceedings of The Royal Society A 461, 575-594.

[159] Rossi, R., \& Iaccarino, G., 2009. Numerical simulation of scalar dispersion downstream of a square obstacle using gradient-transport type models. Atmospheric Environment 43, 2518-2531. 
[160] Rossi, D., Philips, D., \& Iaccarino, G., 2010. A numerical study of scalar dispersion downstream of a wall-mounted cube using direct simulations and algebraic flux models. International Journal of Heat and Fluid Flow 31, 805-819.

[161] Schatzmann, M., Olesen, H., Franke, J. (Eds.), 2009. COST 732 Model evaluation case studies: Approach and results, COST Office, Brussels, Belgium.

[162] Di Sabatino, S., Buccolieri, R., Olesen, H.R., Ketzel, M., Berkowicz, R., Franke, J., Schatzmann, M.K., Schlunzen, H., Leitl, B., Britter, R., Borrego, C., \& Margari, A., 2011. COST 732 in practice - The MUST model evaluation exercise. International Journal of Environment and Pollution 44, 403-418.

[163] Pavageau, M., Rafailidis, S., \& Schatzmann, M., 1997. A comprehensive experimental databank for the verification of urban car emission dispersion models. International Journal of Environment and Pollution 8(3-6), 738-746.

[164] AIAA, 1998. Guide for the verification and validation of computational fluid dynamics simulations. American Institute of Aeronautics and Astronautics, AIAA, Reston, VA (AIAA-G-077-1998)

[165] Oberkampf, W.L., Trucano, T.G., \& Hirsch, C., 2004. Verification, validation, and predictive capability in computational engineering and physics. Applied Mechanics Reviews 57(5), 345-384.

[166] Harms, F., Leitl, B., Schatzmann, M., \& Patnaik, G., 2011. Validating LES-based flow and dispersion models. Journal of Wind Engineering \& Industrial Aerodynamics 99(4), 289-295.

[167] Casey, M., Wintergerste, T. (Eds.), 2000. ERCOFTAC Special interest group on "Quality and trust in industrial CFD": Best Practice Guidelines. ERCOFTAC.

[168] Franke, J., Hellsten, A., Schlunzen, K.H., \& Carissimo, B., 2011. The COST 732 Best practice guideline for CFD simulation of flows in the urban environment: A summary. International Journal of Environment and Pollution 44(1-4), 419-427.

[169] VDI, 2005. VDI Guideline 3783, Part 9, Environmental meteorology - Prognostic microscale wind field models - Evaluation for flow around buildings and obstacles. Commission of Air Pollution Prevention of VDI and DIN, Düsseldorf, Germany, 53pp.

[170] Tominaga, Y., Mochida, A., Yoshie, R., Kataoka, H., Nozu, T., Yoshikawa, M., \& Shirasawa, T., 2008. AIJ guidelines for practical applications of CFD to pedestrian wind environment around buildings. Journal of Wind Engineering \& Industrial Aerodynamics 96, 1749-1761.

[171] Blocken, B., Janssen, W.D., \& van Hooff, T., 2012. CFD simulation for pedestrian wind comfort and wind safety in urban areas: General decision framework and case study for the Eindhoven University campus. Environmental Modelling \& Software 30, 15-34.

[172] Blocken, B., \& Gualtieri, C., 2012. Ten iterative steps for model development and evaluation applied to Computational Fluid Dynamics for Environmental Fluid Mechanics. Environmental Modelling \& Software $33,1-22$.

[173] Robins, A.G., Hall, R., Cowan, I.R., Bartzis, J.G., \& Albergel, A., 2000. Evaluating modelling uncertainty in CFD predictions of building affected dispersion. International Journal of Environment and Pollution 14, 52-64.

[174] Ai, Z.T., \& Mak, C.M., 2013. CFD simulation of flow and dispersion around an isolated building: Effect of inhomogeneous ABL and near-wall treatment. Atmospheric Environment 77, 568-578.

[175] Gousseau, P., Blocken, B., \& van Heijst, G.J.F., 2013. Quality assessment of Large-Eddy Simulation of wind flow around a high-rise building: Validation and solution verification. Computers \& Fluids 79, 120133.

[176] Ai, Z. T., \& Mak, C. M., 2015. Large-eddy Simulation of flow and dispersion around an isolated building: Analysis of influencing factors. Computers \& Fluids 118, 89-100.

[177] Hertwig, D., 2013. On aspects of large-eddy simulation validation for near-surface atmospheric flows. PhD Thesis, 333 pp, Hamburg University.

[178] Hertwig, D., Leitl, B., \& Schatzmann, M., 2011. Organized turbulent structures: Link between experimental data and LES. Journal of Wind Engineering \& Industrial Aerodynamics 99(4), 296-307. 